\title{
Maximum bite force in relation to maximum mouth opening among primary school children
}

\author{
Athraa Hussein Medhat ${ }^{(1)}$ \\ Aseel Haidar M.J. Al Haidar ${ }^{(2)}$
}

\begin{abstract}
Background: The vertical distance between the upper and lower incisal edge of the central incisors when the mouth is opened as wide as possible is called maximum mouth opening (MMO). Any pathological change in the masticatory system had a direct effect on the maximal mouth opening. The aim of this study was to evaluate the relationship between the maximum bite force and the maximum mouth opening among group of children.

Materials and methods: Four hundred children of both genders were included in this study, their age ranged from eight to ten years. Anterior and posterior (right, left) bite force were measured using bite force sensor. Maximum mouth opening was evaluated by electronic digital caliper. Data was statistically analyzed by descriptive statistics and by using paired t-test and Chi-square test.

Results: The value of Maximum mouth opening was increased with the increasing of age in both genders; however, boys had higher value of Maximum Mouth opening than that of girls. A significant difference was found between genders among 9 years old children concerning the maximum bite force. A weak positive relation was observed between Maximum mouth opening and Maximum Bite Force among the boys in both of the age groups.

Conclusions: In this study, a significant positive correlation was found between Maximum bite force and Maximum Mouth opening for boys, as they had higher mean value of maximum mouth opening and maximum bite force than girls. (Received: 15/12/2018; Accepted: 21/1/2019)
\end{abstract}

\section{INTRODUCTION}

Teeth have an important role in the masticatory system, as they form the occlusal area where the food particles are fragmented, so that the grinding force will depend on the total occlusal area and thus on the number of teeth ${ }^{(1-3)}$. Chewing performance and bite force can influence the development of masticatory function. Chewing is a developmental function and its maturation occurs from learning experiences. If mastication is adequate, it gives stimulus for the proper function to normal development of maxilla and mandible. (1,4) Masticatory function can be predicted by a number of parameters, including bite force ${ }^{(5)}$ and occlusal contact area,the higher the bite force and the larger the occlusal contact area can aid in the more efficient mastication. On the other hand, reduced masticatory function may be related to the smaller occlusal contact area ${ }^{(6)}$.

Maximum mouth opening which is the greater distance between the incisal edges of the upper and lower central incisors (at the midline when the mouth is open widely) ${ }^{(7)}$. It is a simple but important clinical parameter to conduct a thorough conventional oral examination and for the follow-up assessments of the diverse affections of the stomatognathic system.

\footnotetext{
1. Master Student, Department of Pedodontics and Preventive Dentistry, College of Dentistry, University of Baghdad.

2. Assistant Professor, Department of Pedodontics and Preventive Dentistry, College of Dentistry, University of Baghdad
}

Limitation in the mouth opening is one of the early signs of some pathological and/or traumatic conditions that may affect the oral cavity, e.g. temporomandibular disorders (TMD) (8), odontogenic infections ${ }^{(9)}$ trauma ${ }^{(10,11)}$, tumors (12), dental infections, craniofacial malignancies, fractures and myopathies (in the head and neck region) ${ }^{(13)}$. All clinicians dealing with the oral cavity facing various problems when there is a limited mouth opening ${ }^{(14)}$. Till now there is no previous Iraqi studies dealing with this subject .The aim of present study to identify the possible relationship between maximum bite force and maximum mouth opening among children for this reason this study conducted.

\section{MATERIALS AND METHODS}

In total, 400 primary school children aged 8-10 years were selected from (1100) students at ten primary schools in AL-Khalis city/ Diyala /Iraq. After getting the approval from the Scientific Committee of the Pedodontics and Preventive Dentistry Department / College of Dentistry/ University of Baghdad, this cross sectional study was carried out during the period from the end of December 2017 until the end of February 2018. To conduct this study without obstacles, official permission was obtained from the General Directorate of Education of Diyala Governorate. Aims of this study were explained to the school authority to obtain cooperation as much as possible and that was done by a formal document. A singed consent was gained from the 
parents of each student participated in this study to get full information about the child (general health and age) and to examine their children as a part of the study sample without obligation. Examination was done at the students' school. The students were examined intra and extraorally and the exclusion criteria were 1.Children with uncooperative behavior 2.Children with cleft lip and/or palate. 3 .

Facial abnormalities.4. Children who their teeth were present with: congenital defects or deformed teeth, missing, unerupted, or fractured permanent centrals, large carious lesions or presence of large restorations.5.Children who had any prosthesis or orthodontic treatment.6.Children with TMJ problems.

In this study, the bite force were measured using bite force sensor (Loadstar sensor, USA).The device capacity was $100 \mathrm{Kg}$. Children were instructed to bite three times, as hard as possible, on the gauge sensor without moving the head .The measurement was done while the child was sitting on a chair, with straight head and back, when his Frankfort horizontal plane was kept horizontal $^{(15)}$. Biting force of each child was measured alternately three times for the posterior area (right and left) and the anterior area each at 10 seconds intervals and the average of the readings was assumed to be MBF of each child where the teeth at maximum intercuspation according to standard procedure ${ }^{(15)}$. Meanwhile, evaluation of the maximum mouth opening (MMO) was done by asking the child to open the mouth as wide as possible ${ }^{(16)}$, while the child was seated comfortably in the chair resting their head against hard wall surface in an upright position. The maximum distance from the incisal edges of the maxillary and the mandibular central incisors at the midline ${ }^{(7)}$ was measured by using electronic digital caliper (China).

The values of the present study were subjected to statistical analysis by using SPSS version 20 (Statistical Package for Social Sciences) to specify the statistical differences between the two groups. $\mathrm{P}$ value of less than or equal the 0.05 level of significance was considered to be statistically significant.

\section{RESULTS}

Table (1), shows the distribution of the sample according to their age and gender in relation to the maximum mouth opening (MMO). In both of the groups, the girls had the higher maximum value of MMO than that of boys. However, the value of the MMO was increased with increasing of the age in both genders. Table (2), shows that although the maximum bite force (Total) of 8 years boys was larger than that of girls, (106.4 \pm $34.6,104.3 \pm 31$ respectively) the difference was not statistically significant. However, among the age group of 9 years the difference between genders concerning the maximum bite on the anterior area and maximum bite force (total) were statistically significant $(\mathrm{p}=0.01)$.

As shown in Table 3, a significant but weak positive correlation was found between (MMO) and MBF (Total) among boys for both of the age groups.

Table (1): Distribution of the study sample according to age and gender in relation to the maximum mouth opening

\begin{tabular}{|c|c|c|c|c|}
\hline \multirow{4}{*}{$\begin{array}{c}\text { Variable } \\
\text { Number \% }\end{array}$} & \multicolumn{4}{|c|}{ Maximum mouth opening } \\
\hline & \multicolumn{2}{|c|}{8 year } & \multicolumn{2}{|c|}{9 year } \\
\hline & Boy & \multirow{2}{*}{\begin{tabular}{c}
\multicolumn{2}{c}{ Girl } \\
$97 \quad 49.7 \%$
\end{tabular}} & Boy & Girl \\
\hline & $80 \quad 39 \%$ & & $12561 \%$ & $98 \quad 50.3 \%$ \\
\hline Range & 25.40 & 28.40 & 25.90 & 25.60 \\
\hline Minimum & 22.00 & 22.00 & 24.30 & 25.00 \\
\hline Maximum & 47.40 & 50.40 & 50.20 & 50.60 \\
\hline Mean \pm SD & $37.53 \pm 4.65$ & $37.51 \pm 4.93$ & $39.39 \pm 4.76$ & $38.83 \pm 5.29$ \\
\hline
\end{tabular}


Table (2): Maximum bite force by age and gender

\begin{tabular}{|c|c|c|c|c|c|c|c|c|c|c|}
\hline \multirow[b]{2}{*}{ Variable } & \multicolumn{5}{|l|}{8 year } & \multicolumn{5}{|l|}{9 year } \\
\hline & $\begin{array}{c}\text { Boys } \\
\text { Mean } \pm \text { SD }\end{array}$ & $\begin{array}{c}\text { Girls } \\
\text { Mean } \pm \text { SD }\end{array}$ & T-test & df & $\mathbf{P}$ & $\begin{array}{c}\text { Boys } \\
\text { Mean } \pm \text { SD }\end{array}$ & $\begin{array}{c}\text { Girls } \\
\text { Mean } \pm \text { SD }\end{array}$ & T-test & df & $\mathbf{P}$ \\
\hline $\operatorname{MBF}(\mathbf{R})$ & $129 \pm 61.4$ & $114.5 \pm 57.1$ & 1.92 & 87 & $0.1^{\mathrm{NS}}$ & $134.4 \pm 70$ & $121.6 \pm 62.8$ & 1.436 & 220.3 & $0.1^{\mathrm{NS}}$ \\
\hline MBF(L) & $110.9 \pm 49.6$ & $121.7 \pm 56.8$ & -1.35 & 173.5 & $0.1^{\mathrm{NS}}$ & $120.9 \pm 57$ & $115.5 \pm 67.2$ & 0.636 & 169.3 & $0.4^{\mathrm{NS}}$ \\
\hline MBF(A) & $79.2 \pm 35.8$ & $76.5 \pm 28.9$ & 0.544 & 0.53 & $0.5^{\mathrm{NS}}$ & $96.2 \pm 32.6$ & $83.6 \pm 29$ & 3.048 & 220.5 & $0.01 S$ \\
\hline MBF(Total) & $106.4 \pm 34.6$ & $104.3 \pm 31$ & 0.421 & 143.3 & $0.6^{\mathrm{NS}}$ & $117.2 \pm 3$ & $106.8 \pm 3$ & 25.694 & 208 & $0.003^{\mathrm{HS}}$ \\
\hline
\end{tabular}

MBF (R) =Maximum bite force in the right side. MBF (L) =Maximum bite force in the left side. MBF (A) =Maximum bite force in the anterior area. MBF $($ Total $)=$ average maximum bite force. NS =Not significant, $S=$ significant, HS= highly significant, (Significance level=P $\leq \mathbf{0 . 0 5}$ ).

Table.3: Pearson correlation coefficient of maximum mouth opening in relation to maximum bite force

\begin{tabular}{|c|c|c|c|c|c|c|}
\hline \multirow{5}{*}{ 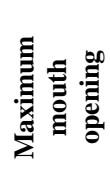 } & Age groups & Genders & MBF(R) & MBF(L) & MBF(A) & MBF(Total) \\
\hline & \multirow{2}{*}{8 Years } & Boys & $-.067^{\mathrm{NS}}$ & $.218^{\mathrm{S}}$ & $.029^{\mathrm{NS}}$ & $.147^{\mathrm{S}}$ \\
\hline & & Girls & $-.008^{\mathrm{NS}}$ & $.054^{\mathrm{NS}}$ & $.064^{\mathrm{NS}}$ & $-.001^{\mathrm{NS}}$ \\
\hline & \multirow{2}{*}{9 Years } & Boys & $.013^{\mathrm{NS}}$ & $.028^{\mathrm{NS}}$ & $-.004^{\mathrm{NS}}$ & $.125^{\mathrm{S}}$ \\
\hline & & Girls & $.024^{\mathrm{NS}}$ & $.151^{\mathrm{S}}$ & $.065^{\mathrm{NS}}$ & $.096^{\mathrm{NS}}$ \\
\hline
\end{tabular}

S=significant, NS=Not significant (Significance level=P $\leq \mathbf{0 . 0 5}$ ).

\section{DISCUSION}

Maximum mouth opening is an important tools for dental clinicians as a preliminary evaluation .It is a relevant references for assessment of the masticatory functional status $(7,17)$. In this study, the values of maximum mouth opening varied considerably among the children. It ranged from a minimum values ( 22 $\mathrm{mm}$ ) among the 8 years old children (both boys and girls), to a maximum value which was $(50.60 \mathrm{~mm})$ among the 9 years old girls .The measurement of MMO of the present study come in accordance with that of other studies ${ }^{(18-}$ ${ }^{22)}$. Lower value of MMO (25.40 to 28.40) at the mixed dentition stage was reported by other studies $(23,24)$. This narrow range value could be due to the small-ranged age groups ( $8-9$ years) of the current study. As reported by Hirsh et al. ${ }^{(22)}$, Cortese et al ${ }^{(24)}$ and Vanderas (25) MMO was related to age, which was in agreement with the present study, which revealed that the MMO was increased with increasing age. In the present study, the significant difference between genders was present only among the age group of 9 years. Meanwhile, gender differences concerning MMO were observed in a few studies $(20,26,27)$, while other studies reported that there was no gender difference in the measurement of MMO among children, which disagreed with the present study $(18,24,26,28)$. The results of the present study showed that a significant

difference was not found between genders in regard to the maximum bite force $\mathrm{MBF}$ on the posterior area (right and left side) among children in both of the age groups. However, gender difference concerning MBF (total) was significant only among the older age group. While some investigators did not find a difference in MBF between genders that disagree with present study ${ }^{(29-32)}$, a significant difference in bite force between boys and girls was reported by several studies ${ }^{(27,33-35)}$ by which the bite force of boys was considerably stronger than that of girls. Results of the present study revealed that there was no clear relationship between the MMO and the MBF, which could be due to the age of the sample (children) and the sample size. However, Fields et al..$^{36}$ previously reported an associated between the presence of larger mouth opening and the presence of a stronger maximum bite force. However, this study was done among adults.

\section{CONCLUSION}

Based on the finding of present study, there was a significant weak positive correlation between maximum mouth opening (MMO) and maximum bite force (MBF Total) among boys in both of the age groups as they had higher mean maximum mouth opening and maximum bite force than girls

\section{REFERENCES}

1. English JD, Buschang PH, Throckmorton GS. Does malocclusion affect masticatory performance. Angle Orthod. 2002; 72: 21-7.

2. Kohyama K, Mioche L, Bourdiol P. Influence of age and dental status on chewing behaviour studied by EMG recordings during consumption of various food samples. Gerodontology, 2003; 20: 15-23.

3. van der Bilt A, Engelen L, Pereira LJ, van der Glas HW, Abbink JH. Oral physiology and mastication. Physiol Behav. 2006; 89: 22-7. 
4. Gavião MB, Raymundo VG, Correr Sobrinho, L. Masticatory efficiency in children with primary dentition. Pediatr Dent. 2001; 23: 499-505.

5. Diernberger, S., Bernhardt, O., Schwahn, C. and Kordass, B.Selfreported Chewing Side Preference and Its Associations with Occlusal, Temporomandibular and Prosthodontic Factors: Results from the Population-Based Study of Health in Pomerania (SHIP-0). Journal of Oral Rehabilitation.2008;35: 613-620.

6. Lujan-Climent, M., Martinez-Gomis, J., Palau, S., Ayuso-Montero, R., Salsench, J. and Peraire, M. Influence of Static and Dynamic Occlusal Characteristics and Muscle Force on Masticatory Performance in Dentate Adults. European Journal of Oral Sciences.2008; 116: 229-236.

7. Placko G, Bellot-Samson V, Brunet S, et al. Normal mouth opening in the adult French population. Rev stomatol Chir Maxillofac. 2005;106(5):267-71.

8. Stegenga B, de Bont LG, Dijkstra PU, Boering G: Short-term outcome of arthroscopic surgery of temporomandibular joint osteoarthrosis andinternal derangement: a randomized controlled clinical trial. Br J OralMaxillofac Surg . 1993; 31:3-14.

9. Al-Nawas B, Walter C, Morbach T, Seitner N, Siegel E, Maeurer M,Krummenauer F: Clinical and microbiological efficacy of moxifloxacinversus amoxicillin/clavulanic acid in severe odontogenic abscesses: apilot study. Eur J Clin Microbiol Infect Dis. 2009; 28:75-82.

10. Chen CT, Feng CH, Tsay PK, Lai JP, Chen YR: Functional outcomesfollowing surgical treatment of bilateral mandibular condylar fractures.Int J Oral Maxillofac Surg. 2011; 40:38-44.

11. Singh V, Bhagol A, Goel M, Kumar I, Verma A: Outcomes of open versus closed treatment of mandibular subcondylar fractures: a prospective randomized study. J Oral Maxillofac Surg . 2010; 68:1304-1309.

12. Acosta-Feria M, Villar-Puchades R, Haro-Luna JJ, Ramos-Medina B, Garcia-Solano E: Limitation of mouth opening caused by osteochondroma of the coronoid process. Oral Surg Oral Med Oral Pathol Oral Radiol Endod.2011;112: 64-68.

13. Kumar A, Dutta S, Singh J, Mehta R, Hooda A, Namdev R. Clinical measurement of maximal mouth opening in children: a pioneer method. JClin Pediatr Dent. 2012; 37(2):171-75.

14. Kumar A, Mehta R, Goel M, Dutta S, Hooda A. Maximal mouth opening in indian children using a new method. J Cranio Max Dis. 2012; 1:79-86.

15. Bakke M, Michler L, Han K, Moller E. Clinical significance of isometric bite force versus electrical activity in temporal and masseter muscle. Scand J Dent Res 1989; 97: 339-351.

16. Placko G, Bellot-Samson V, Brunet $S$, et al. Normal mouth opening in the adult French population. Rev stomatol Chir Maxillofac. 2005; 106 (5):267-71.

17. Machado BCZ, Medeiros AM, Felicio CM. Limites de movimentos mandibulares em crianças. PróFono. 2009;21:189-94.
18. Agerberg G: Maximal mandibular movements in children. Acta Odontol Scand 1974; 32:147-159.

19. Ingervall B: Range of movement of mandible in children. Scand J Dent Res 1970; 78:311-322.

20. Rothenberg LH: An analysis of maximum mandibular movements, craniofacial relationships and temporomandibular joint awareness in children. Angle Orthod 1991; 61:103-112.

21. Keeling SD, McGorray S, Wheeler TT, King GJ: Risk factors associated with temporomandibular joint sounds in children 6 to 12 years of age. Am J Orthod Dentofac Orthop 1994; 105:279- 287.

22. Hirsh C, John MT, Lautensclägher C, List T: Mandibular jaw movement capacity in 10-17 yearold children and adolescents: normative values and the influence of gender, age, and temporomandibular disorders. Eur J Oral Sci 2006; 114:465-470.

23. Muhtarogullary M, Demirel F, Saygili G: Temporomandibular disorders in Turkish children with mixed and primary dentition: prevalence of signs and symptoms. Turk J Pediatr 2004; 46:159163.

24. Vanderas AP. Mandibular movement and their relationship to age and body height in children with or without clinical signs of craniomandibular dysfunction: Part IV.A comparative study.J Dent child 1992; 59:338-341.

25. Hirsch C, John MT, Lautenschlager C, List T. Mandibular jaw movement capacity in 10-yrold children and adolescents:Normative values and the influence of gender, age, and temporomandibular disorders. Eur J Oral Sci. 2006; 114:465-70.

26. Sun KT. The Changes of Bite Force and Associated Influencing Factors of the Chung Hsiao Elementary School Students in the Mixed Dentition Stage. Thesis, China Medical College, Taichung, 2003.

27. Komiyama O,Arai M, Kawara M, Kobayashi K, De Laat A:Pain patterns and mandibular dysfunction following experimental trapezius muscle pain .J Orofac Pain 2005;19:119-126.

28. Kiliaridis S, Kjellberg H, Wenneberg B, Engstrom C. The relationship between maximal bite force, bite force endurance, and facial morphology during growth. Acta Odont Scand 1993;51:323-31.

29. Lindqvist B, Ringqvist M. Bite force in children with bruxism. Acta Odontol Scand 1973;31:255-9.

30. Helle A, Tulensalo T, Ranta R. Maximum bite force values of children in different age groups. Proc Finn Dent Soc 1983; 79:151-4.

31. Brawley RE, Sedwick HJ. Studies concerning the oral cavity and saliva. II. Biting pressure. (2) Measurements of biting pressure in children. Am J Orthod Oral Surg 1940;26: 41-6.

32. Ingervall $\mathrm{B}$, Minder $\mathrm{C}$. Correlation between maximum bite force and facial morphology in children. Angle Orthod 1997; 67:415-24.

33. Shiau YY, Wang JS. The effects of dental condition on hand strength and maximum bite force. Cranio 1993;11:48-54. 
34. Chen CS. The relationship between dental caries prevalence and the relative biting force in children. Chin Med Coll J 1993;2:17-26.
35. Fields HW, Proffit WR, Case JC, Vig KW. Variables affecting measurements of vertical occlusal force. J Dent Res 19 86; 65:135-8.

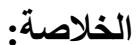

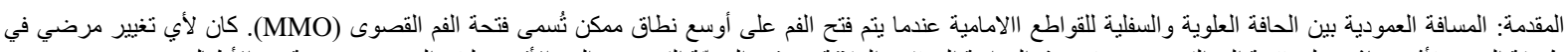

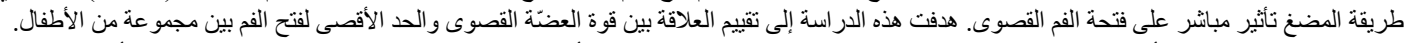

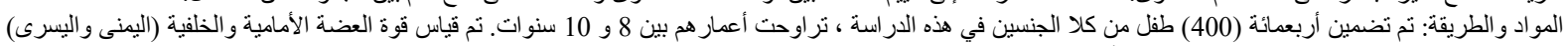

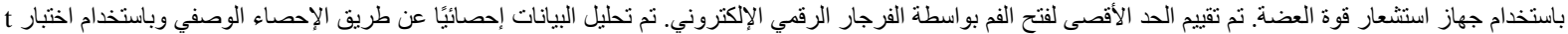
المزدوج و اختبار مربع كابي.

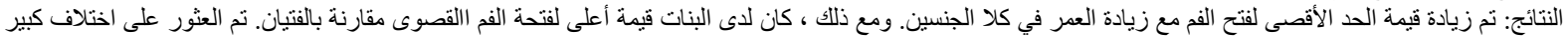

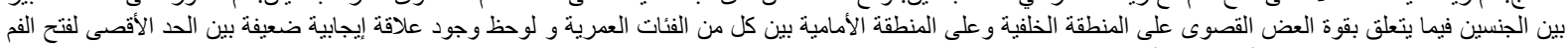

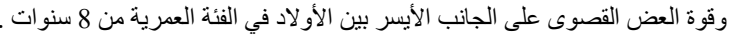

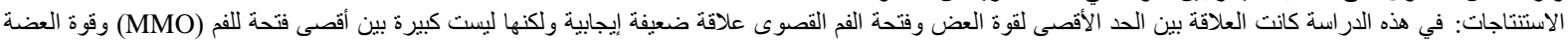

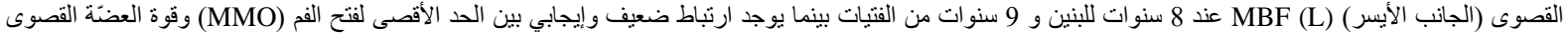

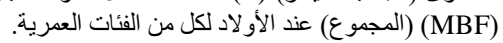

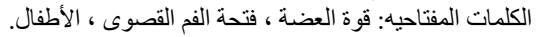

